\section{Esophagitis dissecans superficialis associated with bisphosphonates}

Esophageal injury has been associated with various medications. Here we describe a case of esophagitis dissecans superficialis associated with bisphosphonates.

A 27-year-old woman presented with odynophagia and hematemesis. Her medical history was noteworthy for systemic lupus erythematosus for 9 years, steroidinduced psychosis, and operation for aseptic necrosis of the right femoral head. To prevent osteoporosis, she had been prescribed bisphosphonates. She said that she had been taking the tablet with an inadequate quantity of water. Results of physical examination and routine blood examination were unremarkable. Endoscopy revealed vertical submucosal hematoma in the mid esophagus (Figure 1). Vertical fissures and circumferential cracks with small, peeled, whitish mucosa were observed (Figure 2). A diagnosis of esophagitis dissecans superficialis associated with bisphosphonates was made. Discontinuation of the bisphosphonates and administration of a proton pump inhibitor resulted in rapid recovery, and a repeat endoscopy after a week confirmed complete healing of the esophagitis.

The causes of esophagitis dissecans superficialis include medications, hot beverages, chemical irritants, nasogastric intubation, and autoimmune bullous dermatosis (e.g. pemphigus vulgaris, mucous membrane pemphigoid). Bisphosphonates, as well as potassium chloride and nonsteroidal anti-inflammatory drugs (NSAIDs), are one of the common causes of the esophagitis. Bisphosphonates have been widely prescribed to prevent and treat osteoporosis, but esophageal injury associated with the drugs was reported soon after their approval [1,2]. Possible mechanisms underlying bisphosphonateinduced gastrointestinal events include prolonged contact of the crystalline coating of the tablets with the mucosa, and direct erosive action by dissolved bisphosphonates [3]. A synergistic ulcerogenic

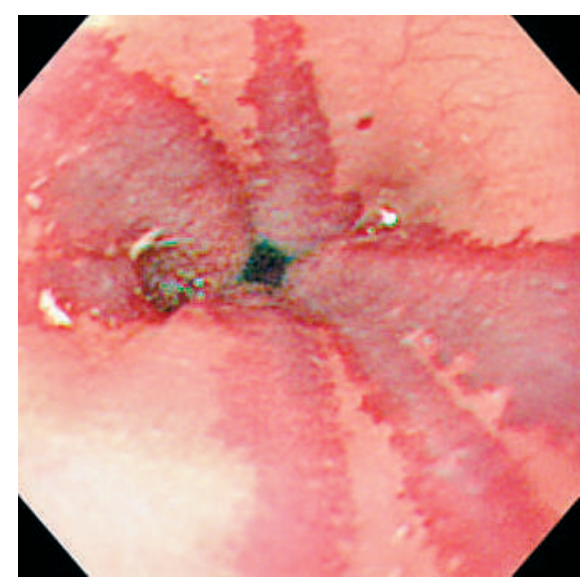

Figure 1 Endoscopic view of vertical submucosal hematoma in the mid esophagus.

potential of concurrent bisphosphonates and NSAIDs should also be considered [4]. Endoscopic features of esophagitis dissecans superficialis vary from superficial inflammation, esophageal cast or ulceration to stricture. To minimize esophageal injury, we should advise patients to take bisphosphonates with an adequate amount of water and to remain in an upright posture for at least 30 minutes after swallowing the tablet.

\section{Endoscopy_UCTN_Code_CCL_1AB_2AC_3AH}

\section{A. Hokama, Y. Ihama, M. Nakamoto, N. Kinjo, F. Kinjo, J. Fujita \\ First Department of Internal Medicine, University of the Ryukyus, Okinawa, Japan.}

\section{References}

1 Maconi G, Porro GB. Multiple ulcerative esophagitis caused by alendronate. Am J Gastroenterol 1995; 90: 1889-1890

${ }^{2}$ de Groen PC, Lubbe DF, Hirsch LJ et al. Esophagitis associated with the use of alendronate. N Engl J Med 1996; 335: 10161021

${ }^{3}$ Graham DY. What the gastroenterologists should know about the gastrointestinal safety profiles of bisphosphonates. Dig Dis Sci 2002; 47: 1665-1678

${ }^{4}$ Graham DY, Malaty HM. Alendronate and naproxen are synergistic for development of gastric ulcers. Arch Intern Med 2001; 161: $107-110$

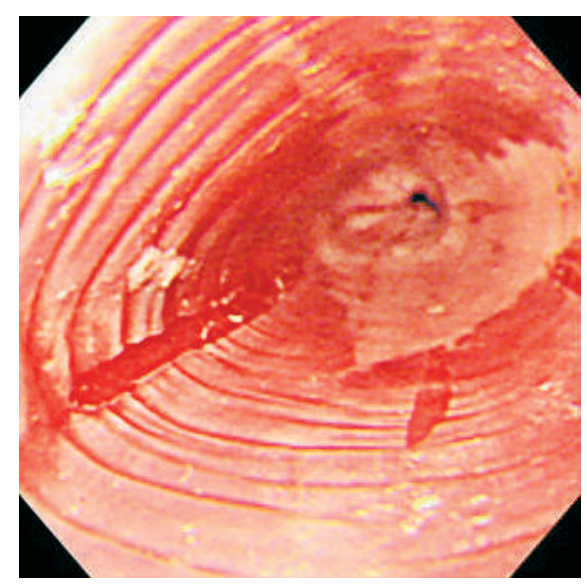

Figure 2 Vertical fissures and circumferential cracks with small, peeled, whitish mucosa were observed.

\section{Corresponding author}

\section{A. Hokama, MD}

First Department of Internal Medicine University of the Ryukyus

207 Uehara

Nishihara, Okinawa 903-0215

Japan

Fax: $\quad+81-98-8951414$

Email: hokama-a@med.u-ryukyu.ac.jp 